\title{
Twenty Years Results of the Israeli-Georgian Program Diabetes in Pregnancy
}

\author{
N. Asatiani , R. Kurashvili , E. Shelestova, M. Dundua, E.Inashvili, A.Kopaleishvili, M. Hod ${ }^{2}$ \\ National center for Diabetes Reserch, Diabetes Researsh, Tbilisi, Georgia \\ ${ }^{2}$ Rabin Medical Center, Department of Obstetrics and Gynecology, Tel-Aviv, Israel
}

Backgraund: The Israeli-Georgian Program Diabetes in Pregnancy was initiated at the Georgian Diabetes Center in 1997, with the aim to provide care for women with diabetes.

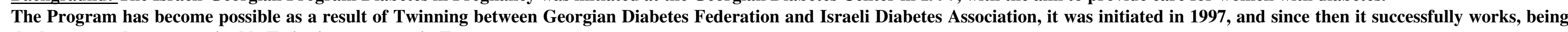
the longest and most sustainable Twinning program in Europe.

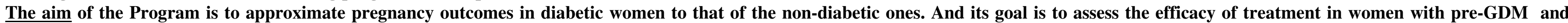
GDM.

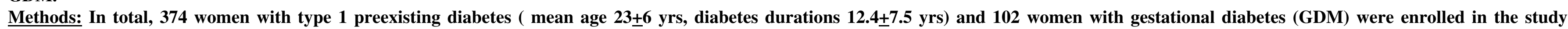
(Tabl.1). The patients were divided into 4 groups (Gr.):

Gr.1 - 210 patients who received specialized pre-conception care; Gr.2 -105 patients enrolled in the program at $<10$ weeks of gestation $\quad(5.6 \pm 2.1$ weeks);

Gr.3 - 59 patients enrolled in the program at > 10 weeks of gestation (19.5+6.1 weeks); Gr.4 - 102 women with GDM ( 20 - 32 weeks of gestations).

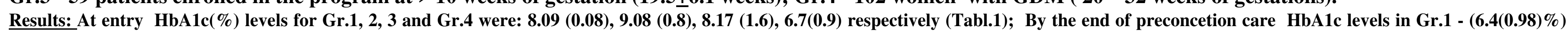
were statistically lower in Gr.2 and $3(P=0.000)$. By term HbA1c levels statistically decreased in all the groups $(P=0.024, P=0.000, P=0.000$, respectively), Fig.1.

At entry percent of the preproliferative retinopathy for Gr.1, 2 and Gr.3 were: 8,09; 13.3 and 11,8\%,respectively; by term the percent has not increased.

The rate of spontaneous abortions was lower in Gr.1 (1.9\%), than in Gr.2 (7.61\%) P=0.0206.

In Gr.1 patients percent of macrosomia was lower, than in Gr.2 and Gr.3 ( P1-2 =0.0074; P1-3 = 0.0101); and in Gr. 1 and 4 (10.47 - 11.7\%) - no statistical difference was observed (Fig.2).

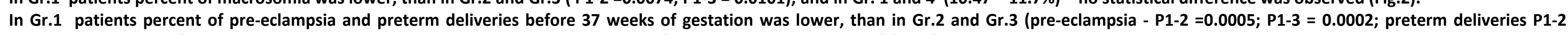
$=0.0014 ; \mathrm{P} 1-3=0.0001$ ). No statistical difference between Gr.1 and Gr.4 was revealed ( P1-4 =0.3748; and $=0.1141$ ) (Fig.3).

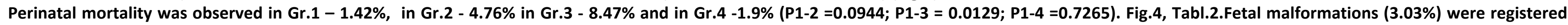
only in Gr.3.

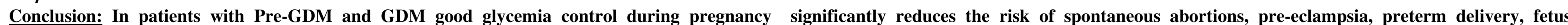

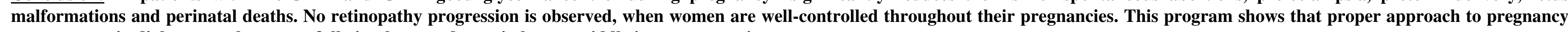
management in diabetes can be successfully implemented even in low-to-middle income countries.

Table 1.

Clinical Date of the Study Population

\begin{tabular}{|r|r|r|r|r|}
\hline & Gr.1 (N=210) & Gr.2 (N=105) & Gr.3 (N=59) & Gr.4 (N=102) \\
\hline Age (years) & $23.9 \pm 5.7$ & $22.5 \pm 4.8$ & $23.7 \pm 5.1$ & $25.1 \pm 5.6$ \\
\hline $\begin{array}{r}\text { Diabetes duration } \\
\text { (years) }\end{array}$ & $10.9 \pm 7.2$ & $11.7 \pm 6.4$ & 9.86 .9 & - \\
\hline $\begin{array}{r}\text { Preconception } \\
\text { care }\end{array}$ & yes & no & no & no \\
\hline $\begin{array}{r}\text { Pre-pregnancy } \\
\text { BMI (kg/m2) }\end{array}$ & $22.6 \pm 3.5$ & $22.03 \pm 2.8$ & $23.1 \pm 1.9$ & $24.8 \pm 4.5$ \\
\hline $\begin{array}{r}\text { HbA1c (\%) before } \\
\text { treatment }\end{array}$ & $8.08 \pm 0.8$ & $9.08 \pm 0.8$ & $8.17 \pm 1.6$ & $6.7 \pm 0.9$ \\
\hline $\begin{array}{r}\text { Preproliferative } \\
\text { retinopathy (\%) }\end{array}$ & 8.09 & 13.3 & 11.86 & \\
\hline $\begin{array}{r}\text { Microalbuminuria } \\
(\%)\end{array}$ & 5.71 & 11.42 & 15.25 & 11.7 \\
\hline
\end{tabular}

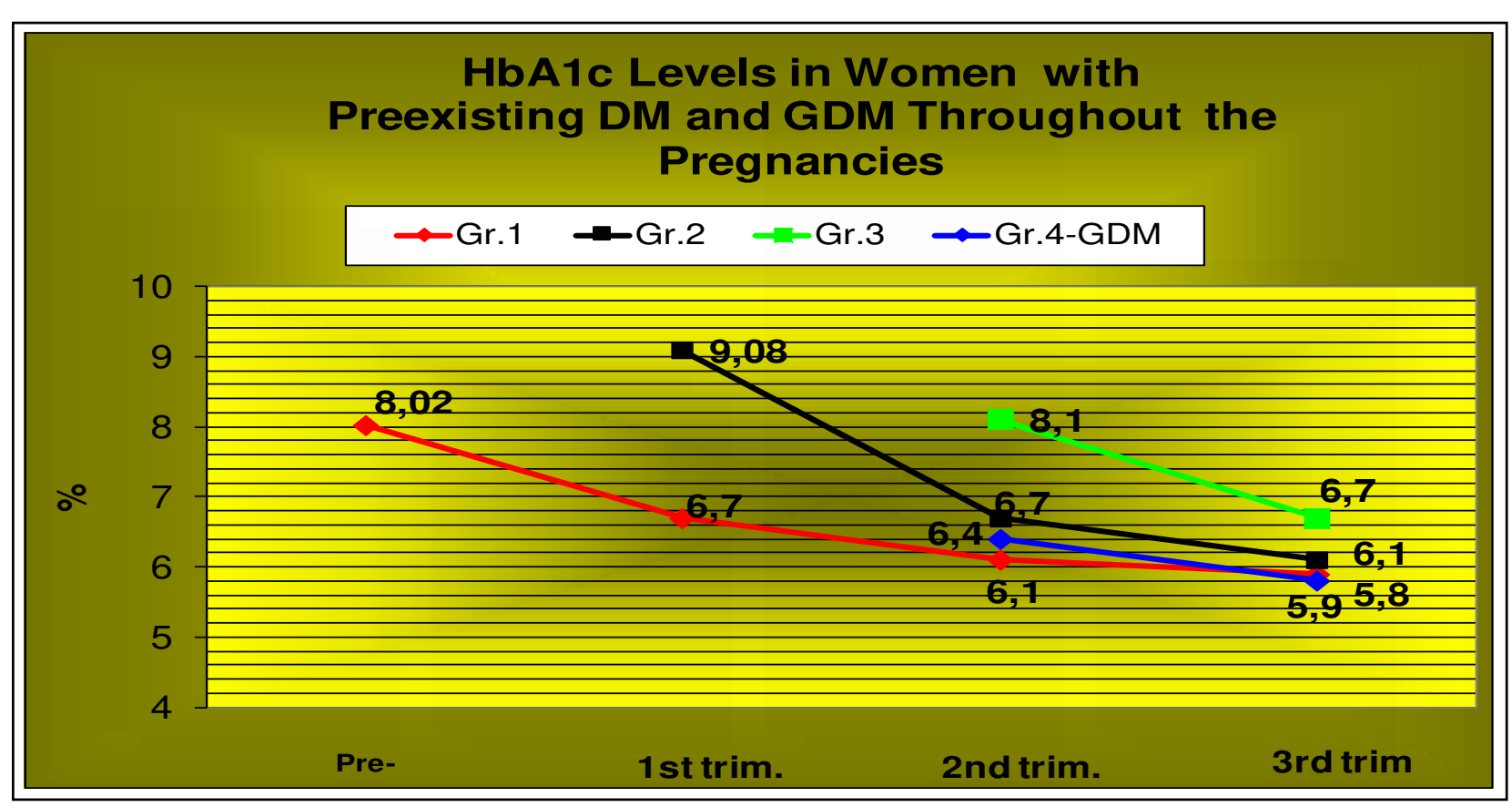

Percent of Preeclampsia and Preterm Delivery in Women with Preexisting DM and GDM

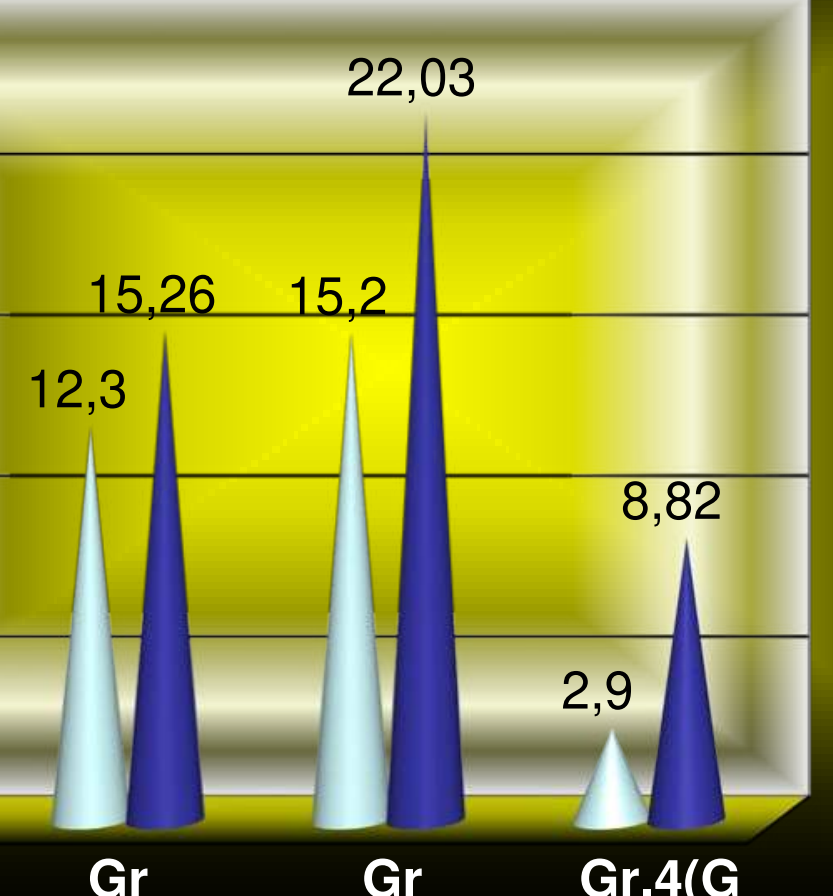

Preeclampsi

- Preterm

delivery
Table 2

Clinical Data in Women with Preexisting DM and Women with GDM

\begin{tabular}{|r|r|r|r|r|} 
& $\begin{array}{r}\text { Gr.1 } \\
\mathrm{N}=210\end{array}$ & $\mathrm{~N}=105$ & $\begin{array}{r}\text { Gr.3 } \\
\mathrm{N}=59\end{array}$ & $\begin{array}{r}\text { Gr.4(GDM) } \\
\mathrm{N}=102\end{array}$ \\
\hline Spont.abort. (\%) & 1.9 & 7.61 & 76.3 & 51.6 \\
\hline $\begin{array}{r}\text { Cesarean } \\
\text { section (\%) }\end{array}$ & 65.1 & 75.3 & & 8.82 \\
\hline $\begin{array}{r}\text { Preterm delivery } \\
(\%)\end{array}$ & 4.28 & 15.23 & 22.03 & \\
\hline Birth weight (g) & $3655 \pm 505.4$ & $3469 \pm 491.1$ & $3487 \pm 642.3$ & $3495 \pm 493.5$ \\
\hline Stilbirth (\%) & 1.42 & 2.8 & 5.08 & 0.98 \\
\hline $\begin{array}{r}\text { Neonatal } \\
\text { death(\%) }\end{array}$ & 0 & 1.9 & 3.39 & 0.98 \\
\hline $\begin{array}{r}\text { Perinatal mortality } \\
\text { per 1000 births }\end{array}$ & 14.2 & & & 84.7 \\
\hline
\end{tabular}

Persent of Macrosomia and Cesarean Section in Women with Preexisting DM and GDM

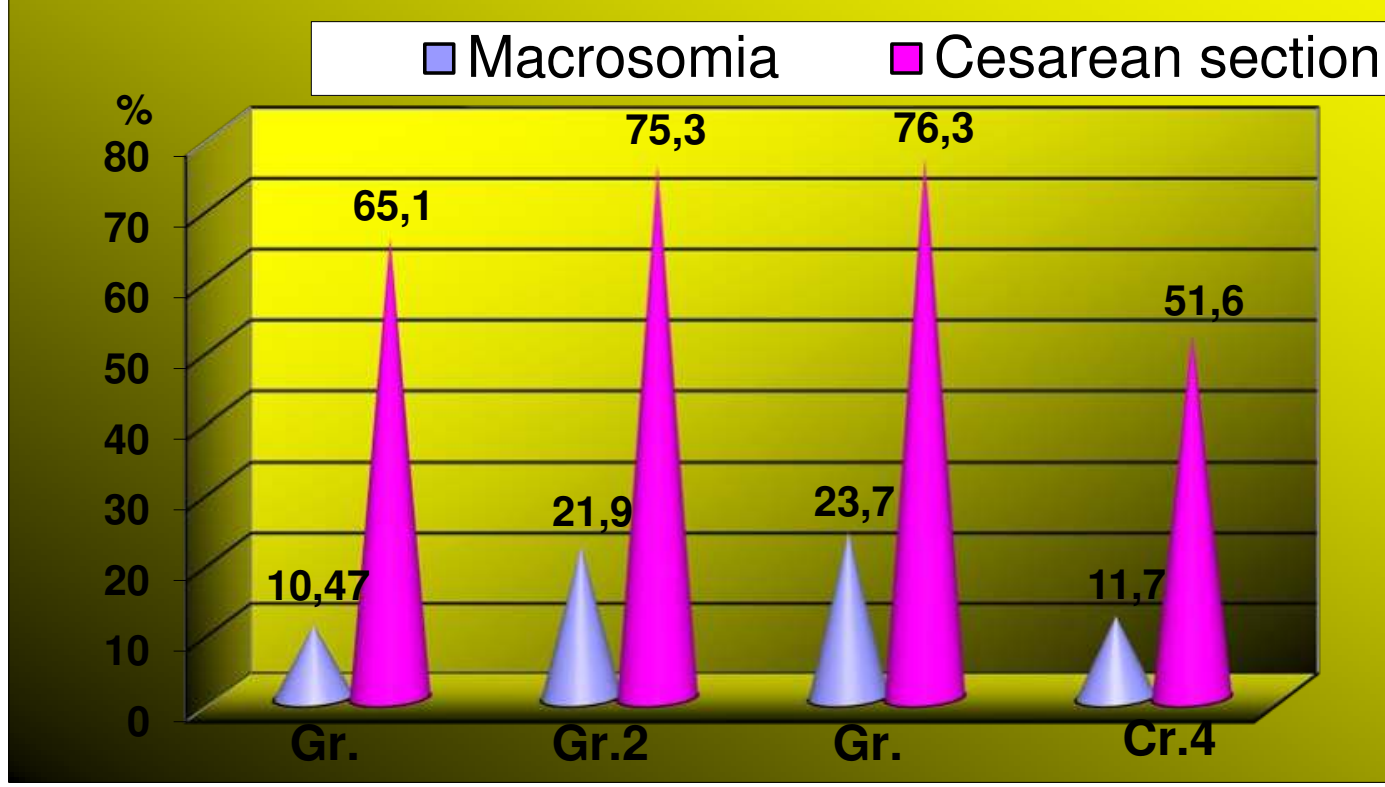

Fig.4 Percent of Spontaneus Abortions and Perinatal Death in Women with Preexisting DM c..d nnnn $\square$ Spontaneus abortion $\square$ Perinatal death

10

$\% 5$

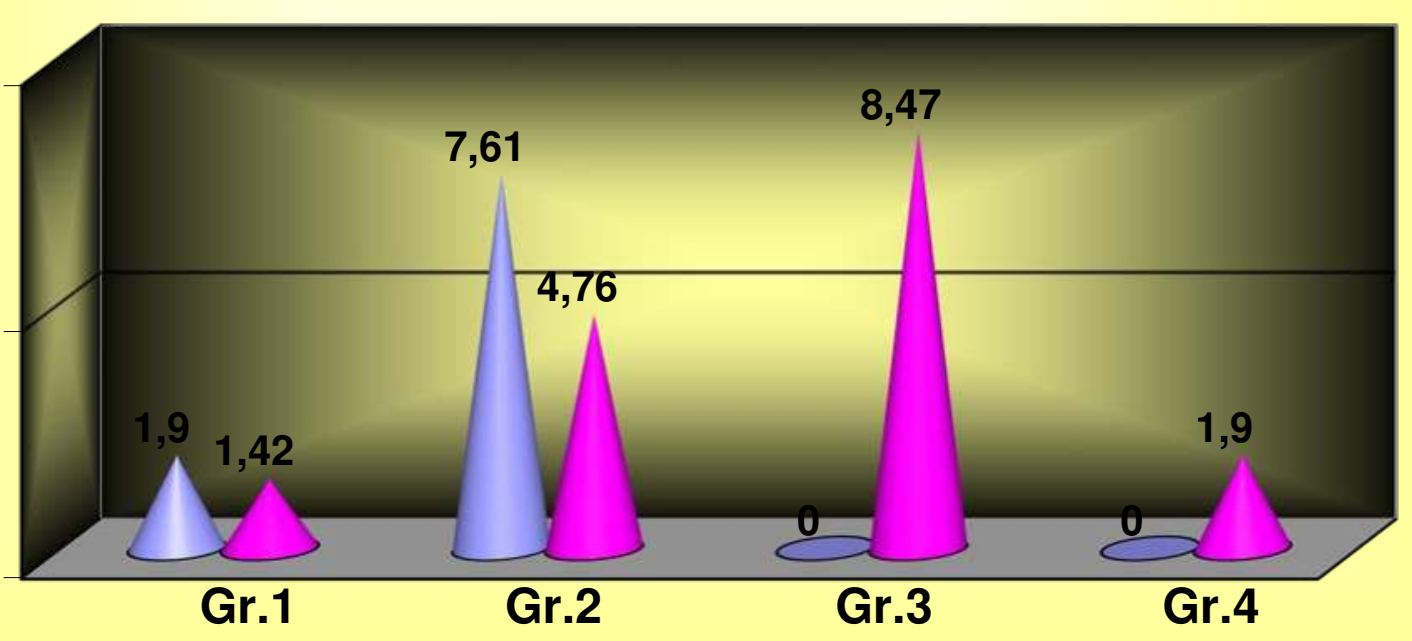

